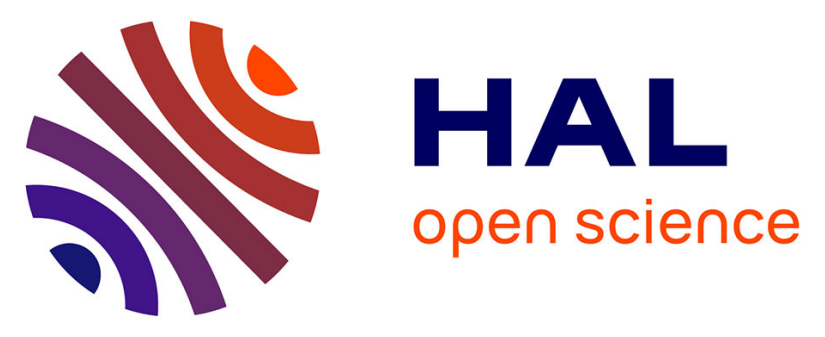

\title{
Felled Trees as a Rockfall Protection System: Experimental and Numerical Studies
}

\author{
Ignacio Olmedo, Franck Bourrier, Frédéric Berger, Ali Limam, David Bertrand
}

\section{To cite this version:}

Ignacio Olmedo, Franck Bourrier, Frédéric Berger, Ali Limam, David Bertrand. Felled Trees as a Rockfall Protection System: Experimental and Numerical Studies. Giorgio Lollino; Daniele Giordan; Giovanni B. Crosta; Jordi Corominas; Rafig Azzam; Janusz Wasowski; Nicola Sciarra. Engineering Geology for Society and Territory, 2, Springer International Publishing, pp.1889-1893, 2015, Landslide Processes, 10.1007/978-3-319-09057-3_335 . hal-02069110

\section{HAL Id: hal-02069110 https://hal.science/hal-02069110}

Submitted on 15 Mar 2019

HAL is a multi-disciplinary open access archive for the deposit and dissemination of scientific research documents, whether they are published or not. The documents may come from teaching and research institutions in France or abroad, or from public or private research centers.
L'archive ouverte pluridisciplinaire HAL, est destinée au dépôt et à la diffusion de documents scientifiques de niveau recherche, publiés ou non, émanant des établissements d'enseignement et de recherche français ou étrangers, des laboratoires publics ou privés. 


\title{
Felled trees as a rockfall protection system: ex- perimental and numerical studies
}

\author{
Ignacio Olmedo $^{1}$, Franck Bourrier ${ }^{1}$, David Bertrand ${ }^{2}$, Frederic Berger ${ }^{1}$, Ali \\ Limam $^{2}$ \\ ${ }^{1}$ IRSTEA Grenoble, 2 rue de la papeterie, 38402 St. Martin d'Heres, France \\ ${ }^{2}$ LGCIE, INSA-Lyon, Av. A.Einstein 69621 Villeurbanne cedex, France
}

In mountain areas, natural hazards, such as snow avalanches, landslides and rockfall threat towns, communication routes and people. It is known that forests have a major capacity to dissipate rockfall energy. Forest maintenance or storms can reduce forest's protective capacity; after such reduction, felled trees can be strategically left on the slopes in order to replace live trees. The efficacy of these devices and their optimal position can be analyzed by developing a numerical model describing the rock-wooden device interaction. To develop a relevant model of these wooden devices when impacted, the research was focused on a rigorous characterization of the fresh wood mechanical properties to recreate the real dynamic response of stems after the impact. Laboratory experiments using a Charpy pendulum assessed the calibration of the numerical model. Experimental results of the impact force and their relation with stems mass and the impact energy level are treated and commented.

Keywords: Rockfall, Impact, Experimental, Numerical model, Felled tree.

\section{Introduction}

Previous studies have been focused on the analysis of the protective function of forest and, more particularly, the tree capacity to dissipate the rocks energy. In forested areas, maintenance of forests is needed to ensure their protective function and health. During this process that consists in removing some trees, the protective capacity of the forest decreases. To compensate the temporary loss of protection, some of the felled trees are left in an oblique position to the slope. The aim of this research is to study the impact of rocks on these devices to determinate their efficacy.

Fresh wood mechanical properties may be characterized to analyze felled trees response to a rock impact. Contrary to dry wood, which has been analyzed in detail because of its importance in construction and industry, few studies concerning the 
rheology of fresh wood and its elasto-plastic mechanical properties can be found in literature.

Impact simulation programs are largely used in civil engineering for structure design and study. Even if numerical simulations allow faster, cheaper and precise results, experimental tests are still needed to validate the numerical models. Due to the complexity to carry out in-field tests and to obtain precise results, laboratory experiments are a good solution to analyze the impacts in detail and precision.

A numerical model is developed to better understand the impact phenomena and the wood mechanical properties and then, to estimate the protection capacity against rockfall of felled trees protection devices. This project aims to study a large amount of different impacts at different impact conditions so numerical calculation duration is an important parameter. The Discrete Element Method (DEM) enables to reduce the simulation duration significantly.

\section{Methodology and results}

\subsection{Numerical model}

A DEM numerical model developed with the YADE-DEM code enables the simulation the interactions of a rock, which is represented by a spherical and rigid body, and a fresh wood stem, represented by a deformable chain of cylinders. An elasto plastic constitutive law, including creeping and plastic rupture, has been implemented on the DEM code to properly describe the fresh wood dynamic behavior. Laboratory experiments assess the calibration and validation of the numerical model as well as a better comprehension of the impact phenomena.

\subsection{Experimental study: impact on simply supported stems}

Experiments were carried out in the LGCIE (Laboratoire de Genie Civil et d'Ingenierie Enviromentale) laboratory at INSA (Institut National des Sciences Appliquées), at Lyon, France. Experiments consisted on the impact on simply supported stems and its behavior during and after the impact was analyzed. The dynamic loading was applied by a Mouton-Charpy pendulum and forces were meas- 
ured by force sensors. Impactor and stem's displacements were measured by a high speed camera.

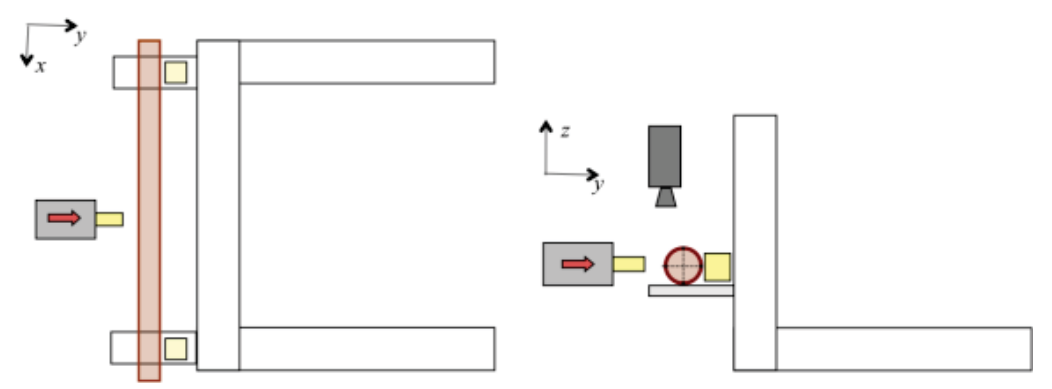

Fig.1 . Experimental device schema
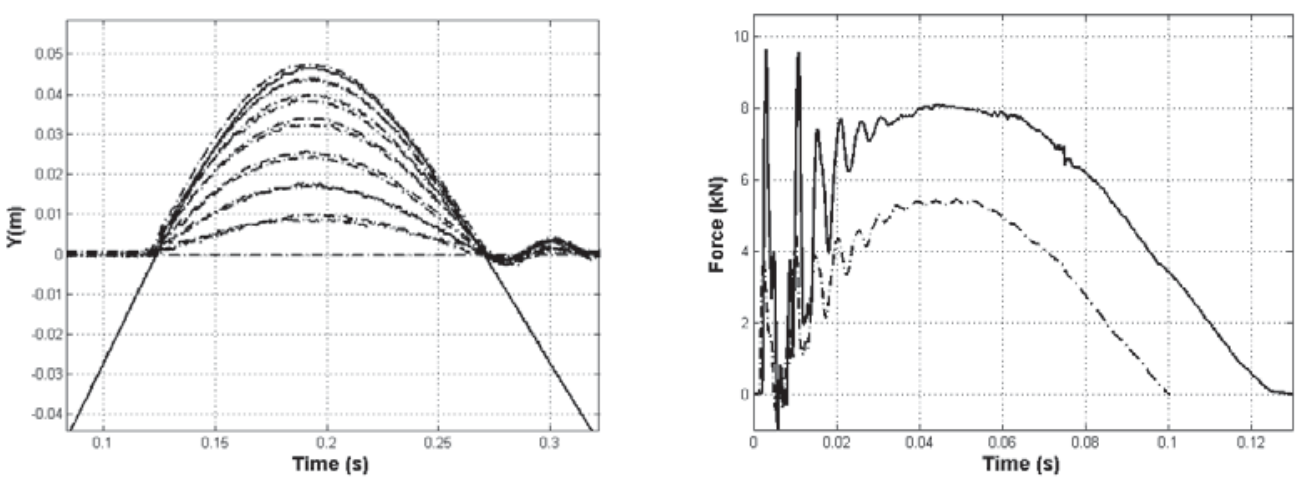

Fig.2. On the left, displacements versus time of 15 points of the stem (dashed) and impactor (solid). On the right, force signal in time for two impacts performed on a same stem at two energy levels: high (solid) and low (dashed).

Impacts on low diameter stems at a HE level leaded to high stress levels due to bending efforts reaching the plastic rupture limit. The rupture of wood fibers can be also observed from the force-time curves as a discontinuity of the signal during the loading phase.

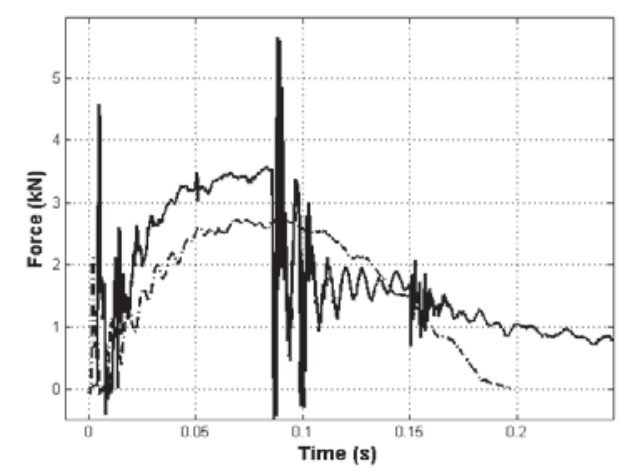

Fig.3. Force signal vs. time, rupture of wood fibers is observed for the high energy impact (solid).

European Beech was the chosen species for this study for being one of the most representative of the French Alps forest population. 43 stems were analyzed and tested and humidity and temperature conditions were controlled in between the cut 
of the trees and the test in order to assure that the mechanical properties did not change. Diameters of stems were in between 3.1 and 9.7 centimeters.

In order to characterize the elasto-plastic behavior of fresh wood, each stem was hit twice. An only elastic deformation was attended with the first impact, at a low impact energy level (LE). The second impact was performed at a higher energy of impact (HE) to achieve an elasto-plastic response of the stems. Impacts were carried out at 95 and 450 Joules respectively.

The Euler-Bernoulli classic motion of beams formulation allow to model the elastic response of the stems under a dynamic loading, $F(x, t)$ :

$$
E I \frac{\partial^{4} y}{\partial x^{4}}+\rho A \frac{\partial^{2} y}{\partial t^{2}}=F(x, t)
$$

Where $E, I, A$ and $\rho$ are the Young's modulii, moment of inertia, section surface and density respectively. A modal recombination model enabled the resolution of the E-B partial differential equation.

Considering that the presented formulation can only represent the elastic response of stems, the LE cases can be completely described by the model while, for the HE impacts, only the first part of the deformation of the wood stem can be estimated by Eq.1. Elastic mechanical parameters were adjusted in order to calibrate the numerical model till the numerical results fit the experimental ones (see Fig.6). So, it was noticed that one mode of vibration is sufficient to describe the stem's response and the hypothesis of only elastic deformation at a low impact energy was confirmed.

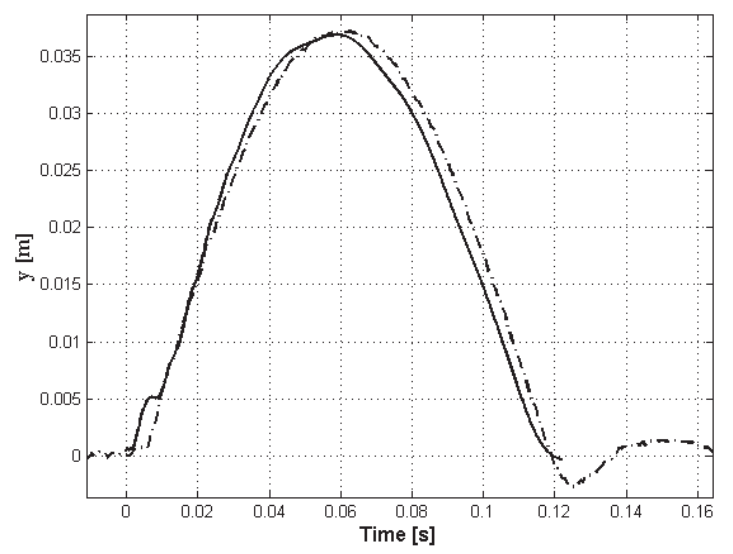

Fig.4: Experimental (dashed) and numerical (solid) deflection during the contact.

Two terms can be identified on the left side of the Euler-Bernoulli (Eq.1): the first, integrates the elastic deformation of the beam and depends on the elastic modulii and the moment of inertia. The latter, takes into consideration the inertial effects and depends on the material density and the section surface. In quasi-static conditions the second term tends to zero. To evaluate the influence of the inertial effects on the stem deformation both terms have been analyzed as shown in Fig.5. 

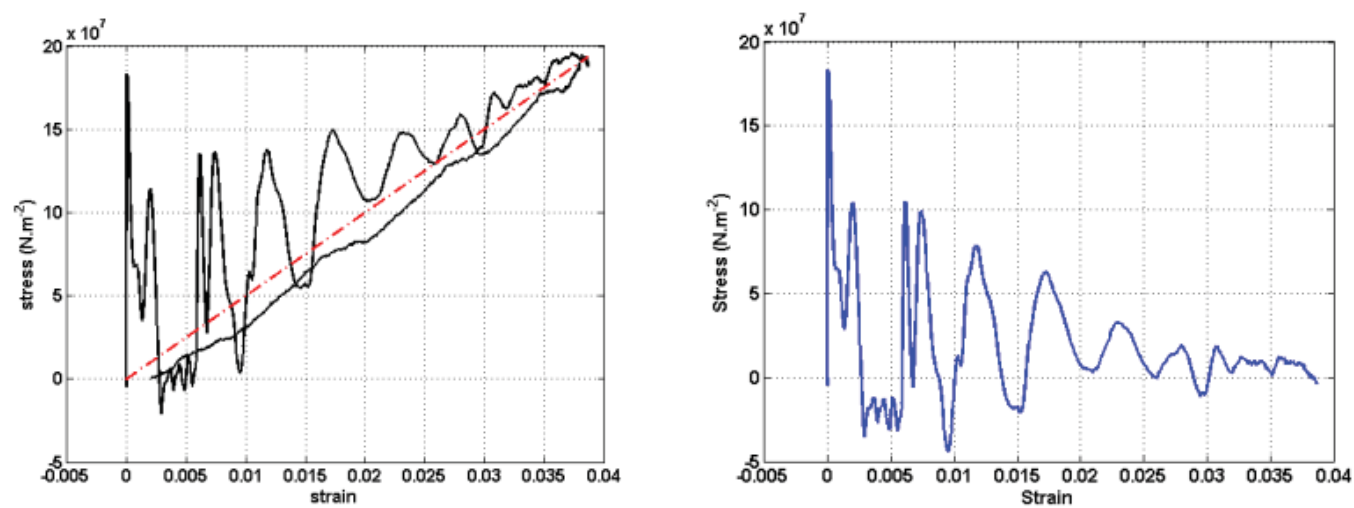

Fig.5: On the left, stress-strain curve and EB equation elastic term contribution (dashed). On the right, inertial effects contribution.

It can be noticed that inertial effects are high at the early beginning of the contact and are strongly damped during the loading phase tending to zero when the maximal deflection is achieved. It can be concluded that the stem response during the unloading is similar to a quasi-static behavior, when deflection is proportional to the applied loading.

By applying the numerical model to HE tests, the limit of the linear elastic limit can be defined. Comparing the experimental and numerical results, it is noticed that at the beginning of the contact, both curves coincide, once the elastic limit is reached, curves diverge due that the numerical model can not represent the effects of plasticity.

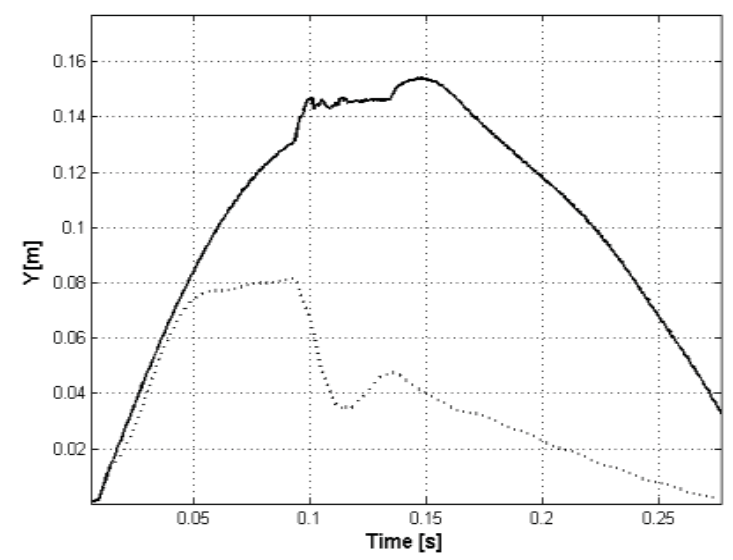

Fig.6: Experimental (solid) and numerical (dashed) stem's deflection vs. time for a HE impact

\section{Conclusions and perspectives}

The obtained results permitted better characterize the impact phenomena before the development of the numerical model. Results permit to get a first approach of the elastic and plastic rupture of fresh wood mechanical properties. 
A second experimental campaign is foreseen to assess the study of the energy dissipation due to the deformation of the wooden device at the impact location. Indentation of the impactor leads to a non negligible plastification of stems (Olsson 2010), so the rock-stem contact law may be characterized. The DEM modeling and the experimental results will assess the study of the contact law.

The validation of the DEM numerical model, integrating the fresh wood constitutive law and rock-stem contact law, will enable to simulate rock impacts on felled trees. The dissipation of energy and the dynamic state of the rock after the impact are the most important aspects to be considered for risk management and rock propagation studies. This model will be integrated on the rock trajectographic tools in order to estimate the rock trajectory on a real slope equipped with felled trees devices. These simulations will allow the analysis of rockfall protection capacity of these devices for real scenarios.

\section{References}

Abrate S. Impact on composite structures, Cambridge university. Press,1998

Olsson R. Analytical model for delamination growth during small mass impact on plates,IJSS 47 (2010)p.2884

Chopra D. Dynamics of structures, Prentice Hall, 1995.

Lalane M, Mechanical vibrations for engineers, Wiley Interscience Publ. 1983

Bertrand D, Bourrier F, Olmedo I, Brun M, Limam A. Experimental and numerical dynamic analysis of a live tree stem impacted by a Charpy pendulum. IJSS 2013;50(10):1689-1698.

Jancke O. Quantifying the mechanical resistance of coppice trees against rockfall. Hamburg University 2012 